\title{
Implication of Interleukin-4 in Wound Healing
}

\author{
Véronique Salmon-Ehr, Laurent Ramont, Gaston Godeau, Philippe Birembaut, \\ Moncef Guenounou, Philippe Bernard, and François-Xavier Maquart
}

Laboratoire de Biochimie et Biologie Moléculaire et Laboratoire de Recherche Biomédicale en DermatologieUPRESA CNRS 6021 (VS-E, LR, PBe, F-XM), and Laboratoire d'Histologie INSERM U314(PBi), and Laboratoire des Cytokines (UPRES-EA 2070) (MG), IFR-53 Biomolécules, Faculté de Médecine, Reims Cedex; and Laboratoire de Biochimie et Analise d'Images (GG), Faculté d'Odontologie, Montrouge, France

SUMMARY: Interleukin-4 (IL-4) is a pleiotropic cytokine that is able to activate connective tissue cells and stimulate the accumulation of extracellular matrix macromolecules. In this report, the expression of IL-4 in normal wound healing was studied by immunohistochemistry. The effects of exogenous IL-4 or IL-4 antisense oligonucleotides administration were also studied in mouse experimental wounds. IL-4 expression was detected in the lower dermis below the wound as early as Day 1 after wounding. IL-4 expression was maximal by Day 4, then decreased progressively, and completely disappeared by Day 21 after wounding. Topical administration of IL-4 on experimental wounds in mice significantly accelerated the rate of healing, whereas IL-4 antisense oligonucleotides significantly inhibited healing. These results demonstrate that IL-4 may be implicated in normal wound healing. (Lab Invest 2000, 80:1337-1343).

$W$ ound healing is the result of a spatially and temporally controlled sequence of events, resulting in a limited activation of cells. This process is controlled by interactions between different cell types and by the interactions of cells with the extracellular matrix. An uncontrolled activation of connective tissue cells in wound healing may result in hypertrophic scars or keloids.

Interleukin-4 (IL-4) is a 20 kDa multifunctional cytokine, that displays pleiotropic biological effects (Peyron and Banchereau, 1994) on not only hematopoietic but also nonhematopoietic cells, especially fibroblasts, in which it stimulates extracellular matrix synthesis (Fertin et al, 1991; Gillery et al, 1992). It is secreted mainly by mast cells, T-lymphocytes, and basophilic polymorphonuclears. It has been found to be overexpressed in a wide variety of fibrotic conditions in which mast cells and T-lymphocytes play a central role, such as scleroderma (Salmon-Ehr et al, 1996), radiation-induced pulmonary fibrosis (Buttner et al, 1997), and liver fibrosis (Henderson et al, 1991). Preliminary data from our laboratory suggested that IL-4 expression is strongly increased in keloids (Salmon-Ehr et al, 1998).

The aim of the present study was to investigate the expression of IL-4 during normal wound healing in mice. In a second part, the effects of IL-4 and IL-4

Received May 30, 2000.

The first two authors contributed equally to this work.

This work was supported by grants from CNRS and the University of Reims Champagne-Ardenne.

Address reprint requests to: Prof. François-Xavier Maquart, UPRESA CNRS 6021, IFR 53-Biomolécules, Faculté de Médecine, 51, Rue Cognacq Jay, 51095 Reims Cedex, France. Fax: 33032678 85 39; E-mail: fmaquart@chu-reims.fr antisense oligonucleotides were studied in an acute wound model in mice.

\section{Results \\ IL-4 Is Transiently Expressed during Normal Wound Healing in Mice}

In normal mouse skin, IL-4 immunoreactivity was seen in some sebaceous glands only. After wounding, it appeared as soon as Day 1 and was maximal at Days 2 to 4 (Fig. 1). The label was localized in the granuloma beyond the wound and in dermal spindle-shaped cells with a fibroblastic appearance. Most of these cells were located near the capillary vessels in the lower dermis. IL-4 expression decreased progressively after Day 4 and totally disappeared by Day 21 .

\section{IL-4 Accelerates Wound Healing in Mice}

Application of $250 \mathrm{ng} \mathrm{IL-4}$ once daily for 4 days on experimental wounds in mice induced a rapid and dramatic increase in the formation of the granulation tissue. Measurement of the wound areas demonstrated that the closure of wounds treated with IL-4 was significantly accelerated in comparison with controls (Fig. 2). Microscopic examination of the granulation tissue showed an increased inflammatory reaction in wounds treated with IL-4 (Fig. 3), with an increased cell density as measured by automated image analysis: $108 \pm 16$ cells per $10,000 \mu \mathrm{m}^{2}$ in IL-4-treated wounds vs $78 \pm 12$ in controls $(p<0.01)$.

The relative area fraction occupied by collagen fibers at Day 4 was measured by automated image analysis on 6 different zones of each slide. In wounds treated with IL-4, this area was significantly increased 


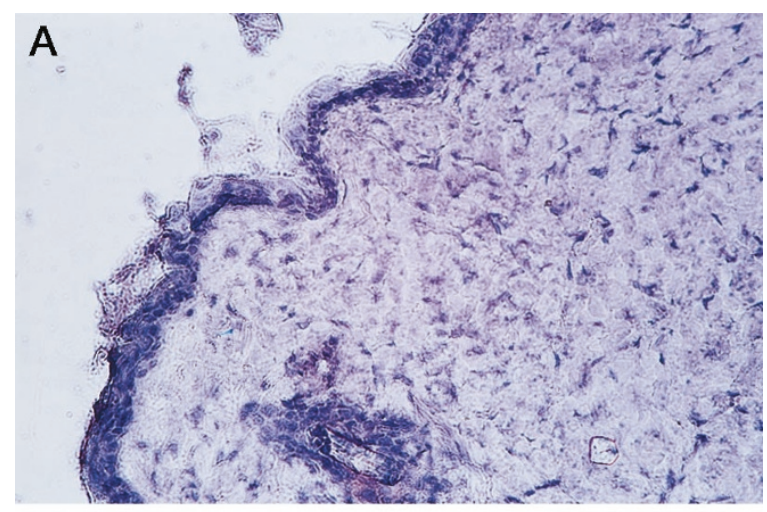

B

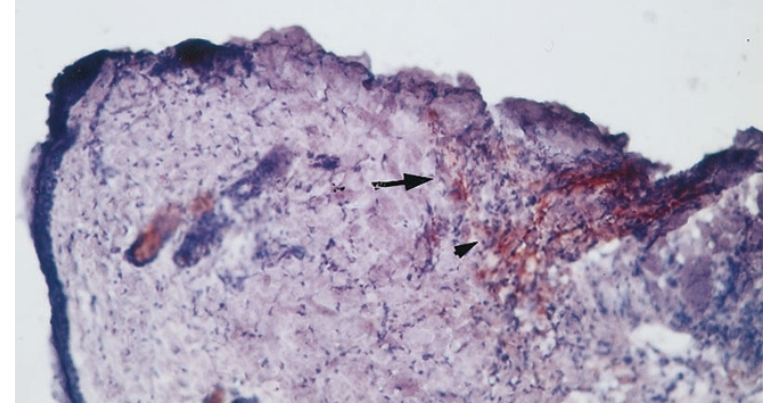

\section{Figure 1.}

Immunohistochemical study of the distribution of interleukin-4 (IL-4) expression during wound healing in mice. Immunoperoxidase staining was performed with a monoclonal rat anti-mouse-IL-4 antibody, on normal unwounded skin (control) (A), and on wounded skin at Day 2 after injury (B). Staining for IL-4 is indicated (arrows). (Original magnification, $\times 100$ ). Intense staining was observed under the wound as soon as Day 1 , was maximal by Days $2-4$, and disappeared completely after 3 weeks.

compared with the controls: $33 \pm 7$ vs $21 \pm 6$ (arbitrary units), $p<0.01$.

\section{IL-4 Antisense Oligonucleotides Decrease Wound Healing in Mice}

Wounds received the application of either IL-4 sense or antisense oligonucleotides and were observed after 7 days. Wounds treated with the antisense were characterized by a delayed wound healing when compared with the sense control group (mean wound areas: $73 \pm 37.5$ vs $41.3 \pm 23.8 \mathrm{~mm}^{2}, p<0.02$ ). Standard histological examination and automated image analysis showed a significant reduction of the cellular density: $51.4 \pm 12.4$ cells per $10,000 \mu \mathrm{m}^{2}$ in the control (sense) group vs $23.5 \pm 2.9$ for the antisense-treated group (Fig. 4). Sirius red staining showed that, in normal dermis, the collagen fibers of the deeper layers had a well defined, nearly horizontal, orientation, whereas this organization was totally disrupted in the primary matrix of the wounds treated with IL-4-antisense oligonucleotides (Fig. 5). In the IL-4 antisense-treated group, the area fraction occupied by collagen fibers was decreased by $38 \%$ $( \pm 18.25)$ compared with the control $(p<0.001)$. Immunohistochemistry showed that the expression of $\mathrm{IL}-4$ in the antisense-treated wounds was nearly totally

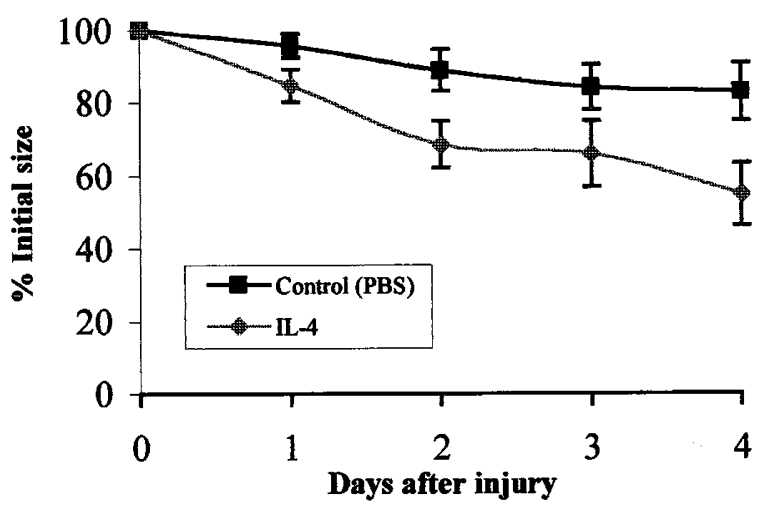

Figure 2.

IL-4 accelerates wound closure in mice. The wound areas were measured every day after wounding in six controls (black squares) and seven IL-4-treated mice (gray diamonds). Mean wound areas \pm SEM were expressed as percentages of initial wound areas at Day 0. IL-4 was applied at the dose of $250 \mathrm{ng}$ per day every day for 4 days. A significant acceleration of wound closure was observed in IL-4-treated animals.

suppressed in comparison with untreated wounds (Fig. 6). No difference was observed between the two groups in the re-epithelialization rate of the wounds.

In an additional experiment, topical IL-4 (250 ng per wound) was added to the wound bed simultaneously with IL-4-antisense oligonucleotides $(50 \mu \mathrm{g}$ per wound). Mice were killed at Day 2 and the wound areas were measured. As shown in Table 1, topical $\mathrm{IL}-4$ could completely overcome the negative effect of the IL-4 antisense treatment.

\section{Discussion}

Tissue repair proceeds as an ordered sequence of events, beginning with an inflammatory response in the wound area and followed by granulation tissue formation, accumulation of new connective tissue, tissue remodeling, and scar formation. The different steps of murine wound healing have been well characterized by previous works of Schilling et al (1953). During the first day after wounding, the wound bed is promptly filled with fibrinous material and contains macrophages, leukocytes and lymphocytes. Fibroblasts at the periphery of the wound begin proliferation after 24 to 36 hours. During the next 6 days, a marked increase in the number of fibroblasts and the formation of new vessels occur. From the 7th to 13th days, there is an intense deposition of collagen and other extracellular matrix components. The re-epithelialization and closure of the wound occurs during the same period. Extracellular matrix remodeling may then last for several weeks or months.

The control of the wound-healing process is still incompletely known. Regulation of the deposition of extracellular matrix components in vivo is complex: it involves interactions among many different cell types and between cells and extracellular matrix macromolecules, and it necessitates the coordinated expression of many different soluble mediators that either stimulate or inhibit this process. Keloids may be caused by a dysregulation of this sequence of events, particularly 
A
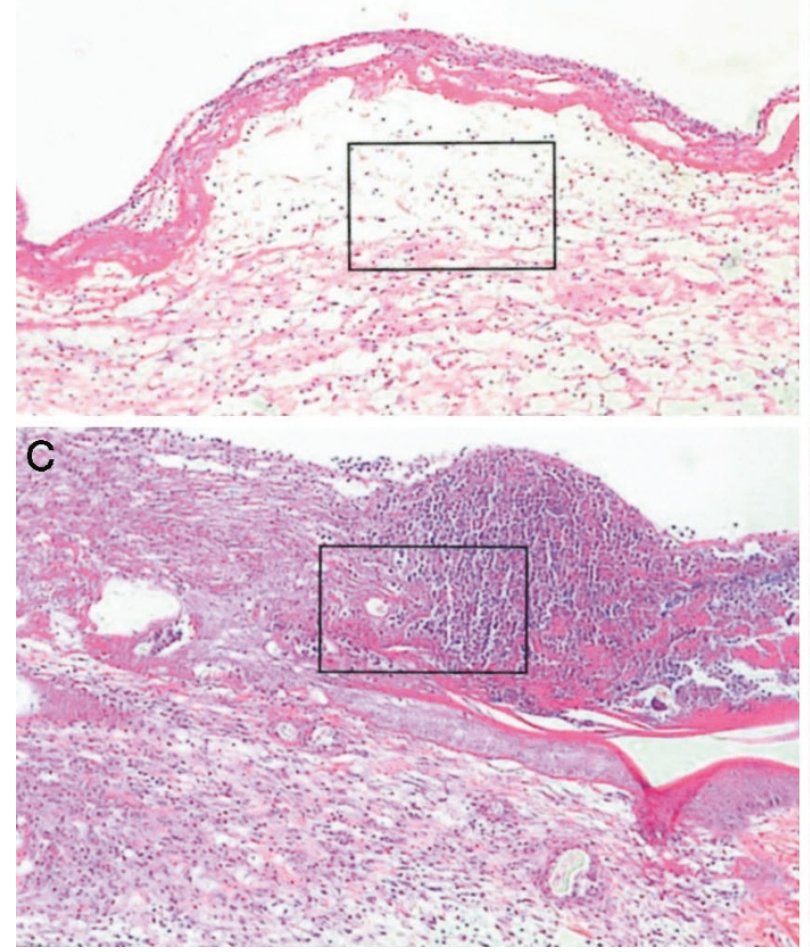
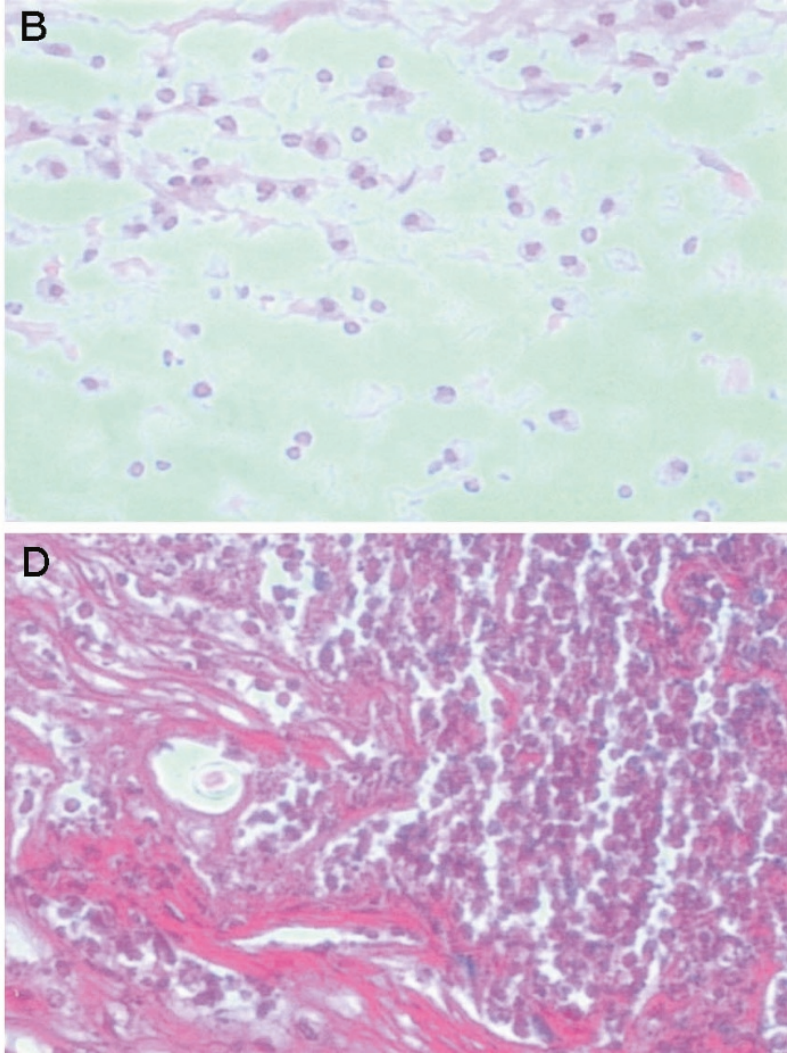

\section{Figure 3.}

Histological examination of wounds treated with PBS (controls) (A and B) or IL-4 (C and D) at Day 4. B and D are higher magnification of the areas outlined in A and $\mathrm{C}$, respectively (original magnification, $\times 250$ for $\mathrm{A}$ and $\mathrm{C} ; \times 400$ for $\mathrm{B}$ and $\mathrm{D}$ ). IL-4 was applied at the dose of $250 \mathrm{ng}$ per day every day for 4 days. Tissue sections were stained by hematein-erythrosin-safran. Cellular density was increased in IL-4-treated wounds in comparison with controls.

by an uncontrolled expression of some cytokines or growth factors such as transforming growth factor- $\beta$ (Bettinger et al, 1996). Increased expressions of basic fibroblast growth factor (Akimoto et al, 1999) and IL-15 (Castagnoli et al, 1999) were also reported in hypertrophic scars. Also, preliminary data from our laboratory suggested that IL-4 expression may be increased in keloids (Salmon-Ehr et al, 1998).

IL-4 has been shown to enhance the production of collagen and other extracellular matrix macromolecules by human fibroblasts from different tissues (Fertin et al, 1991; Gillery et al, 1992; Sempowski et al, 1994; Serpier et al, 1997). It may also induce a myofibroblast differentiation (Mattey et al, 1997), which is an essential feature of granulation tissue. It induces fibroblast chemotaxis (Postlethwaite and Seyer, 1991) and decreases matrix metalloproteinase biosynthesis (Lacraz et al, 1992). Such properties suggested that IL-4 could be involved in connective tissue formation during normal and pathologic wound healing. To our knowledge, this is the first study of IL-4 expression during normal wound healing.

We have shown that IL-4 is strongly expressed during the early period of normal wound healing and disappears after wound closure. In normal skin, IL-4 immunoreactivity was found only in some sebaceous glands. This red positivity was found whatever the treatment of the slides, which suggests that it may be a nonspecific labeling. We cannot, however, exclude the possibility that some IL-4 may be expressed in sebaceous glands.

We observed that most of the labeling with the monoclonal anti-IL-4 antibody was found in cells with a fibroblast-like phenotype, most of them located near the capillary vessels in the lower dermis. In a previous study, we found a similar localization of IL-4 expression in scleroderma skin (Salmon-Ehr et al, 1996), a disease in which connective tissue cells are highly activated. Recent data from Ong et al (1998) showed that administration of neutralizing IL-4 antibodies prevents dermal collagen deposition in a mouse model of scleroderma.

Since IL-4 possesses several characteristics required for an activator of wound healing, we decided to study the effects of IL-4 application on experimental wounds in mice. For that purpose, we measured the rapidity of wound closure, as indicated by the reduction of wound area. Although it is known that the skin heals from below a wound as well as from the sides, the speed of wound closure remains the best criteria for appreciating the efficiency of healing in clinical practice (Lindblad, 1999). Wound area was measured by automated image analysis (see "Materials and Methods" section). Our results demonstrated a significant acceleration of the rate of healing in wounds receiving a topical application of IL-4. These results 

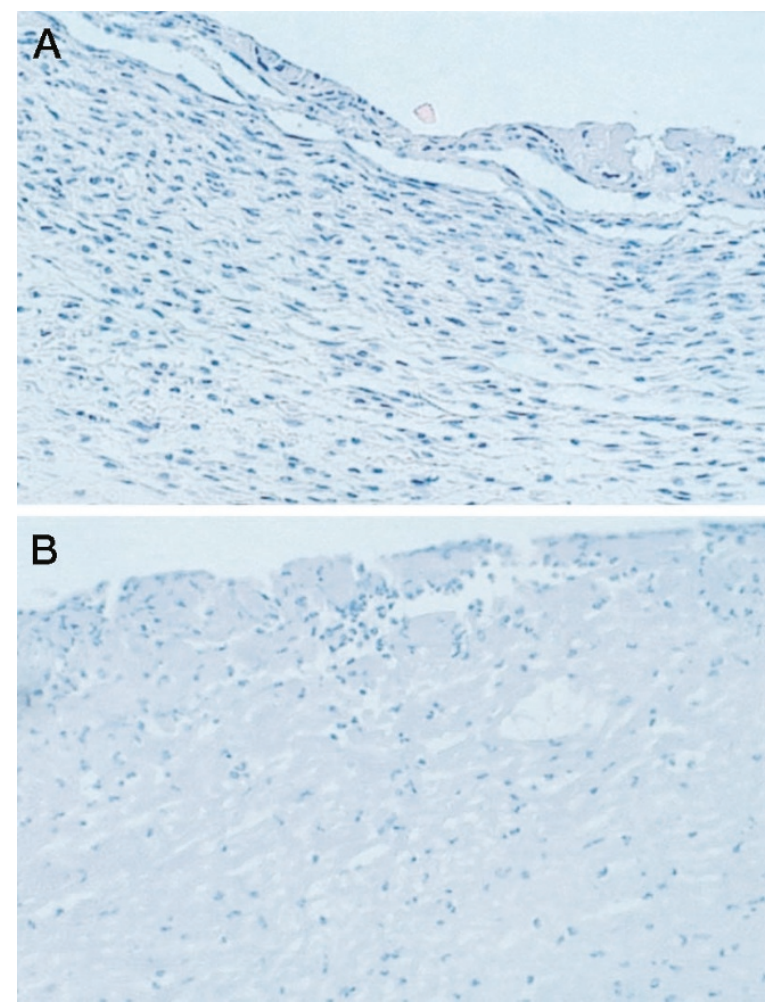

Figure 4.

Histological aspect of wounds treated with IL-4 sense (A) or antisense (B) oligonucleotides (original magnification, $\times 250$ ). Oligonucleotides were applied at the dose of $50 \mu \mathrm{g}$ in $50 \mu \mathrm{l}$ PBS mixed with $0.04 \mathrm{~g}$ carboxymethyl cellulose. Tissue sections were stained with hematoxylin-eosin. A significant reduction of the cell density was observed in the antisense-treated wounds.

are in agreement with those of Kucukcelebi et al (1995) who demonstrated that IL-4 was able to reverse the retardation of wound closure in a model of bacterially infected wound.

Antisense oligonucleotides are useful tools for examining the requirement for expression of some specific genes in various biologic processes. They allow the specific inhibition of the biosynthesis of a protein by adding to the cells a synthetic nucleotide complementary to a portion of the mRNA encoding for the protein. The oligonucleotides penetrate into the cells and are thought to hybridize with the mRNA and block the recognition of the normal message. They were previously used successfully to study the effects of specifically suppressing the expression of transforming growth factor- $\beta 1$ in wounds (Chung et al, 1997). Our results suggest that decreasing the expression of IL-4 in a wound by IL-4 antisense oligonucleotide treatment results in a decrease in the rate of wound healing. The delay in wound closure seems linked to a decrease of the inflammatory reaction, since far fewer inflammatory cells were present in the wound bed receiving the antisense.

The present study indicates that IL-4 production may be implicated in normal wound healing. IL-4 and/or specific IL-4 antisense oligonucleotides might be potential therapeutic agents for the treatment of wound-healing defects.
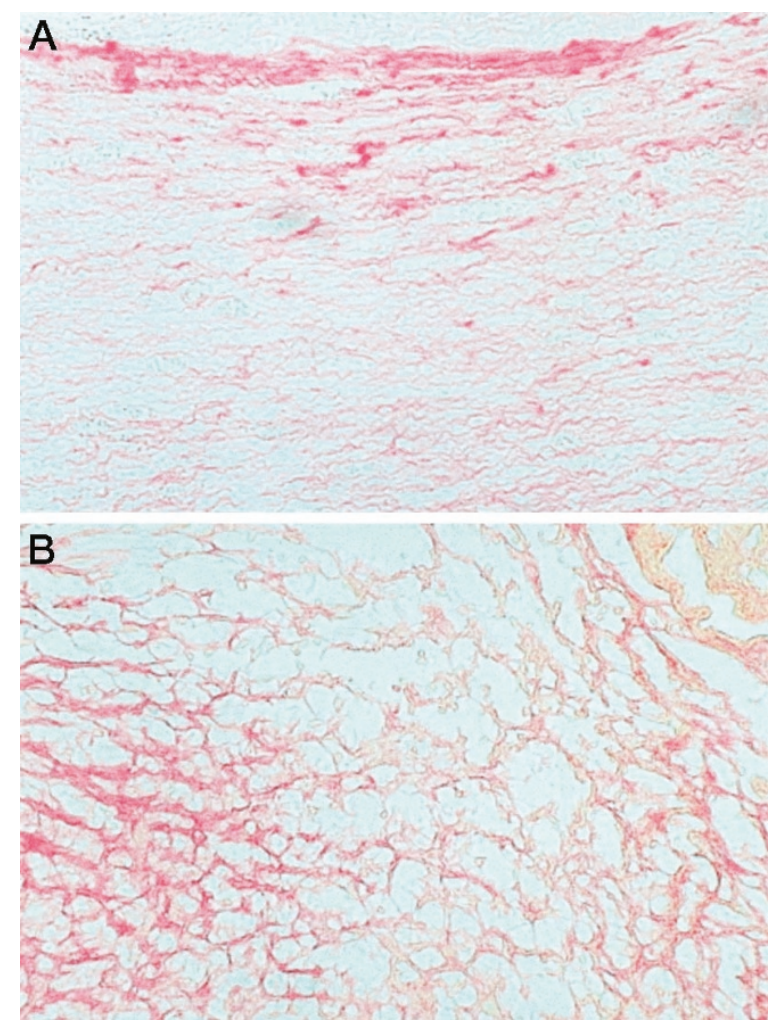

Figure 5.

Sirius red staining of the wounds treated by IL-4 sense (A) or antisense (B) oligonucleotides (original magnification, $\times 250$ ). Collagen bundles were poorly organized in wounds treated with IL-4 antisense compared with the IL-4 sense control group.

\section{Materials and Methods}

\section{Animals}

The experiments were conducted with strict adherence to the principles of laboratory animal care. Male Swiss mice weighing 20 to $40 \mathrm{~g}$ were used. They were purchased from Centre d'Elevage Dépré (St. Doulchard, France). Animals were individually caged and given food and water ad libitum. They were kept in a room with constant temperature and humidity. All mice were acclimatized to our laboratory conditions for 1 week before starting the experiments.

\section{Investigation of IL-4 Expression during Wound Healing in Mice}

Mice $(n=4)$ were anesthetized with ethyl ether. After shaving the hair, six single, full-thickness, 8-mm diameter excisional wounds were made with a sterile biopsy punch (Stiefel, Nanterre, France) on the middorsum of each mouse and left undressed. Wounds were biopsied on Days 1, 2, 4, 8, 12, and 21. Specimens were frozen in liquid nitrogen and stored at $-70^{\circ} \mathrm{C}$ until immunohistological staining.

\section{Investigation of IL-4 Effects on Wound Healing in Mice}

Mice $(n=13)$ were anesthetized and prepared for surgery as previously described. A single, full- 

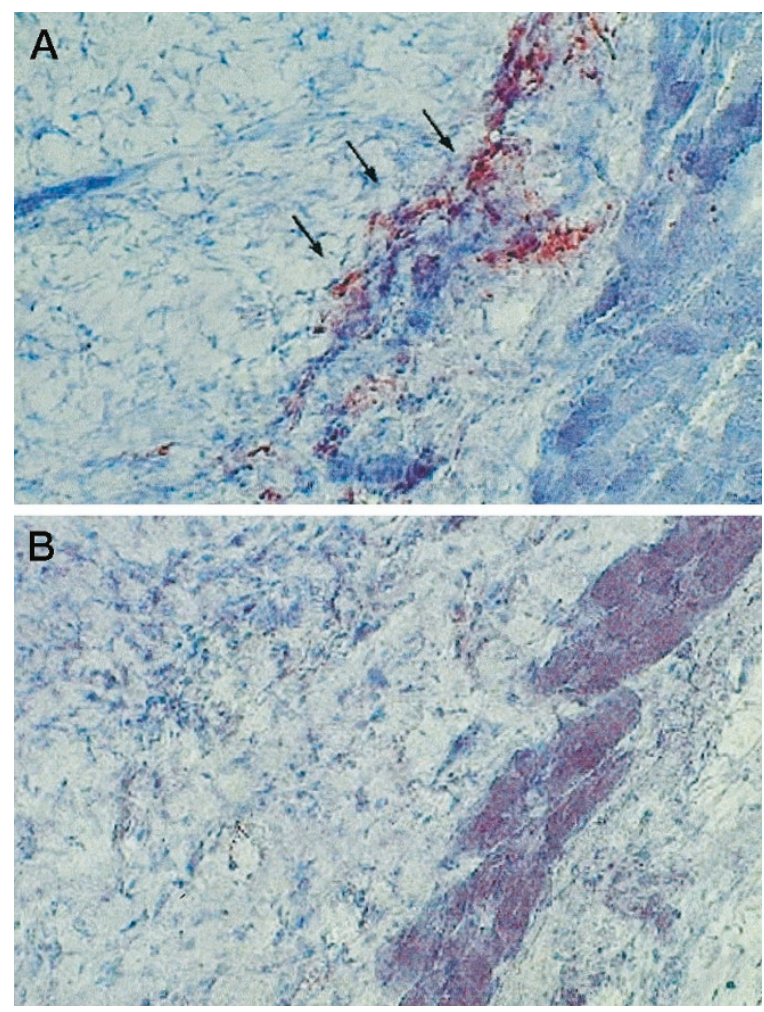

\section{Figure 6 .}

Immunohistochemical study of the effects of IL-4-antisense oligonucleotides on IL-4 expression in mouse wounds. Wounds received either the vehicle alone (A) or $50 \mu \mathrm{g}$ of antisense oligonucleotides in $50 \mu \mathrm{l}$ PBS mixed with $0.04 \mathrm{~g}$ carboxymethyl cellulose (B) (original magnification, $\times 250$ ). Mice were killed at Day 2 and IL-4 expression in the wound assessed by immunohistochemistry. Staining for IL-4 is indicated (arrows). A strong decrease of IL-4 expression was observed in antisense-treated wounds.

Table 1. Topical IL-4 Overcomes Negative Effect of IL-4 Antisense Treatment on Wound Closure ${ }^{a}$

\begin{tabular}{|c|c|c|}
\hline \multicolumn{3}{|c|}{ Wound area at Day 2 (\% of initial wound area) } \\
\hline $\begin{array}{c}\text { Controls } \\
\text { (vehicle only) } \\
(\mathrm{n}=7)\end{array}$ & $\begin{array}{l}\text { IL-4-antisense } \\
\quad(\mathrm{n}=5)\end{array}$ & $\begin{array}{l}\text { IL-4-antisense }+ \\
\text { topical IL-4 } \\
(n=6)\end{array}$ \\
\hline $88.9 \pm 2.2$ & $107.7 \pm 5.5^{\star}$ & $91.5 \pm 2.7$ \\
\hline
\end{tabular}

thickness, $8 \mathrm{~mm}$-diameter excisional wound was made with a sterile biopsy punch on the mid-dorsum of each mouse.

Seven mice were treated by application of IL-4 (Genzyme Corporation, Cambridge, Massachusetts), at a dose of $250 \mathrm{ng}$ in $50 \mu \mathrm{l}$ of PBS (GIBCO, CergyPontoise, France), mixed in $0.04 \mathrm{~g}$ low-viscosity carboxymethyl cellulose (Sigma-Aldrich, La Verpillère, France). IL-4 was applied topically once daily for 4 consecutive days after injury. Wounds were covered first with an occlusive $8 \mathrm{~mm}$ aluminium Finn chamber (Epitest Ltd Oy, Tuusula, Finland) and then with a transparent adhesive dressing (Visulin; Wuhrlin-
Soplamed, Courbevoie, France) and an elastic dressing (Fisch-Smith \& Nephew, Vibraye, France). Every day the dressing was removed for wound assessment. The wound margin was traced on a glass slide and the wound area measured with an image analyzer. Mean wound areas were expressed as percentages of the initial wound areas at Day 0.

A group of six mice (controls) was processed identically, but they received $50 \mu$ PBS in $0.04 \mathrm{~g}$ carboxymethyl cellulose, without IL-4. Animals were killed 24 hours after the last dressing, and large biopsies of the wound areas were performed for histological examination.

\section{Investigation of IL-4 Antisense Oligonucleotides Effects on Wound Healing in Mice}

Oligonucleotides were synthesized by Oligo Express (Grenoble, France). The sequences used were as follows: 5'-TAC GCT GTG TTG GGG-3' for the antisense, and 5'-ATG CGT CTC AAC CCC-3' for the sense oligomers. The antisense sequence is complementary to those surrounding the AUG codon of murine IL-4 mRNA. Their inhibiting effect on IL-4 production by rat spleen cells was previously demonstrated (Benbernou et al, 1993).

Mice $(n=15)$ were anesthetized and prepared for surgery as previously described. A single, fullthickness, 8-mm diameter excisional wound was made with a sterile biopsy punch on the mid-dorsum of each mouse.

Eight mice were treated by application of IL-4 antisense oligonucleotides, at a dose of $50 \mu \mathrm{g}$ in $50 \mu \mathrm{l}$ of PBS mixed in $0.04 \mathrm{~g}$ low-viscosity carboxymethyl cellulose. Wounds were covered as previously described. Seven days after wounding, animals were killed. Dressing was removed for wound examination. The margin of the wound was traced on a glass slide, and the wound area was measured on an image analyzer (Berteretche et al, 1995). Mean wound areas were expressed as percentages of initial wound areas at Day 0. Large biopsies of the wounded areas were performed for histological examination.

A group of seven mice (controls) received $50 \mu \mathrm{g}$ of IL-4 sense oligonucleotides in $50 \mu$ l of PBS mixed in $0.04 \mathrm{~g}$ carboxymethyl cellulose and were processed identically. In a complementary experiment, a group of six mice received simultaneously an application on the wound bed of the IL-4 antisense oligonucleotides (50 $\mu \mathrm{g})$ and topical IL-4 (250 ng) in the same vehicle as above. The rate of healing was then compared with that of control mice treated with the vehicle only and also with that of mice treated with the IL-4-antisense oligonucleotides only.

\section{Immunohistochemical Staining}

For immunohistological staining, skin biopsy specimens were cut in 5- $\mu \mathrm{m}$ sections, using a cryostat apparatus (Cryocut 1800; Leica, Nussloch, Germany), put on a coated-glass slide, and fixed in acetone. Mouse IL-4 was detected in skin sections with 
an avidin-biotin peroxidase kit (Dako Corporation, Carpinteria, California) and a rat monoclonal antimouse-IL-4 antibody (Genzyme Corporation, Cambridge, Massachusetts). After the endogenous peroxidase was blocked with hydrogen peroxide, a blocking solution of goat serum in $0.05 \mathrm{~mol} / \mathrm{L}$ TRIShydrochloride buffer, $\mathrm{pH} 7.6$, was applied for 5 minutes at room temperature. The primary antibody was used at a concentration of $10 \mu \mathrm{g} / \mathrm{mL}$ in Dulbecco's PBS and applied for 1 night at $4^{\circ} \mathrm{C}$. After being washed extensively in Dulbecco's PBS, the glass slides were incubated with a biotinylated rabbit antirat IgG, followed by the streptavidin-enzyme complex according to the instructions of the manufacturer. The sections were then incubated in aminoethylcarbazole in $0.3 \%$ (wt/vol) hydrogen peroxide for 10 minutes to produce the peroxidase reaction. The sections were counterstained with Mayer hematoxylin. Negative control sections were stained with Dulbecco's PBS instead of the primary antibody solution.

The labeling intensity was evaluated independently by two pathologists, both blinded to the woundhealing stage. Ten fields were examined at $\times 100$ magnification for each.

\section{Morphological and Image Analysis}

Tissue samples were fixed in $4 \%$ paraformaldehyde. Tissue was dehydrated in increasing grades of ethanol and chloroform and embedded in paraffin. Tissue sections were cut at $5 \mu \mathrm{m}$ and stained with hemateinerythrosin-safran for routine histological analysis and by hematoxylin-eosin for cell density measurement. For the image analysis of collagen bundles, the slides were also stained with Sirius red F3ba, according to the method of Junqueira et al (1979).

Automated image analysis was used to determine the morphometric parameters. The analysis was performed directly on the histological sections observed under a Zeiss standard 14 microscope equipped with a CF 126 video camera (Sophretec, Bezons, France). The black and white images generated by the camera were converted into 256 gray levels using a Sophretec MVM 600 image memory, transferred to a BFM 186 microcomputer (Sophretec), and analyzed using mathematical morphology software (Serra, 1982). This program calculated the area fraction occupied by collagen fibers, ie, pixels of collagen $/ 256^{2}$ pixels. For cell density measurement, cell nuclei were defined by their form factor and gray level and then counted automatically by the program. At least six different measurements were performed for every tissue section analyzed.

\section{Statistical Calculations}

All data were expressed as mean \pm standard deviation. Statistical analysis of mice data was performed by the one-tailed Student's $t$ test.

\section{References}

Akimoto S, Ishikawa O, lijima C, and Miyachi Y (1999). Expression of basic fibroblast growth factor and its receptor by fibroblasts, macrophages and mast cells in hypertrophic scar. Eur J Dermatol 9:357-362.

Benbernou N, Matsiota-Bernard P, and Guenounou M (1993). Effect of cytokine-specific antisense oligonucleotides on the immunoglobulin production by rat spleen cells in vitro. Biochimie 75:55-61.

Berteretche MV, Hornebeck W, Pellat B, Blanchet-Bardon C, and Godeau G (1995). Histomorphometric parameters and susceptibility to neutrophil elastase degradation of skin elastic fibres from healthy individuals and patients with Marfan syndrome, Ehlers-Danlos type IV, and pseudoxanthoma elasticum. Br J Dermatol 133:836-841.

Bettinger DA, Yager DR, Diegelmann RF, and Cohen IK (1996). The effect of TGF-beta on keloid fibroblast proliferation and collagen synthesis. Plast Reconstr Surg 98:827-833.

Buttner C, Skupin A, Reimann T, Rieber EP, Unteregger G, Geyer P, and Frank KH (1997). Local production of interleukin-4 during radiation-induced pneumonitis and pulmonary fibrosis in rats: Macrophages as a prominent source of interleukin-4. Am J Respir Cell Mol Biol 17:315-325.

Castagnoli C, Trombotto C, Ariotti S, Millesimo M, Ravarino D, Magliani G, Negro Ponzi A, Stella M, Teich-Alasia M, Novelli F, and Musso T (1999). Expression and role of IL-15 in post-burn hypertrophic scars. J Invest Dermatol 113:238-245.

Chung HT, Choi BM, Jun CD, Park SD, and Rim JS (1997). Antisense transforming growth factor- $\beta 1$ in wound healing. Antisense Nucleic Acid Drug Dev 7:257-261.

Fertin C, Nicolas JF, Gillery P, Kalis B, Banchereau J, and Maquart FX (1991). Interleukin-4 stimulates collagen synthesis by normal and scleroderma fibroblasts in dermal equivalents. Cell Mol Biol 37:823-829.

Gillery P, Fertin C, Nicolas JF, Chastang F, Kalis B, Banchereau J, and Maquart FX (1992). Interleukin-4 stimulates collagen gene expression in human fibroblast monolayer cultures. Potential role in fibrosis. FEBS Lett 302:231-234.

Henderson GS, Conary JT, Summar M, McCurley TL, and Colley DG (1991). In vivo molecular analysis of lymphokines involved in the murine immune response during Schistosoma mansoni infection. I. IL-4 mRNA, not IL-2 mRNA, is abundant in the granulomatous livers, mesenteric lymph nodes, and spleens of infected mice. J Immunol 147:992-997.

Junqueira LC, Bignolas G, and Brentani RR (1979). Picrosirius staining plus polarization microscopy, a specific method for collagen detection in tissue sections. Histochem J 11:447-455.

Kucukcelebi A, Harries RHC, Hennessey PJ, Phillips LG, Broemeling LD, Listengarten D, Ko F, Narula S, and Robson MC (1995). In vivo characterization of interleukin-4 as a potential wound healing agent. Wound Repair Regen 3:49-58.

Lacraz S, Nicod L, Galve de Rochemonteix B, Baumberger C, Dayer JM, and Welgus HG (1992). Suppression of metalloproteinase biosynthesis in human alveolar macrophages by interleukin-4. J Clin Invest 90:382-388.

Lindblad WJ (1999). How does one determine efficacy? Wound Repair Regen 7:77.

Mattey DL, Dawes PT, Nixon NB, and Slater H (1997). Transforming growth factor beta and interleukin-4 induced alpha smooth muscle actin expression and myofibroblastlike differentiation in human synovial fibroblasts in vitro: Modulation by basic fibroblast growth factor. Ann Rheum Dis 56:426-431. 
Ong C, Wong C, Roberts CR, Teh HS, and Jirik FR (1998). Anti-IL-4 treatment prevents dermal collagen deposition in the tight-skin mouse model of scleroderma. Eur $\mathrm{J}$ Immunol 28:2619-2629.

Peyron E and Banchereau J (1994). Interleukin-4: Structure, function, and clinical aspects. Eur J Dermatol 4:181-188.

Postlethwaite AE and Seyer JM (1991). Fibroblast chemotaxis induction by human recombinant IL-4. J Clin Invest 87:2147-2152.

Salmon-Ehr V, Serpier H, Nawrocki B, Gillery P, Clavel C, Kalis B, Birembaut $P$, and Maquart FX (1996). Expression of interleukin-4 in scleroderma skin specimens and scleroderma fibroblast cultures. Arch Dermatol 132:802-806.

Salmon-Ehr V, Capon F, Birembaut P, Kalis B, Bernard P, and Maquart F. X (1998). Potential role of interleukin-4 in normal and pathologic wound healing (abstract). J Invest Dermatol 110:601.
Schilling J, Fatava BV, and Radakovich M (1953). Studies of fibroplasia in wound healing. Surg Gynecol Obstet 96:143159.

Sempowski GD, Beckman MP, Derdak S, and Phipps RP (1994). Subsets of murine lung fibroblasts express membrane-bound and soluble IL-4 receptors. Role of IL-4 in enhancing fibroblast proliferation and collagen synthesis. J Immunol 152:3606-3614.

Serpier H, Gillery P, Salmon-Ehr V, Garnotel R, Georges N, Kalis B, and Maquart FX (1997). Antagonistic effects of interferon- $\gamma$ and interleukin-4 on fibroblast cultures. J Invest Dermatol 109:158-162.

Serra J (1982). Image analysis and mathematical morphology. London: Academic Press, 55-95. 